\title{
Executive Information Systems: An Evaluation of Current UK Practice Introduction
}

In a recent survey amongst senior executives in the UK, using data as a corporate resource was ranked as the second most important information systems management issue. ${ }^{1}$ Managers are becoming ever more dependent on information, on which to base business decisions, but less able to extract this information from the overwhelming amount of data which they receive. In order to manage this problem, many organisations have introduced an executive

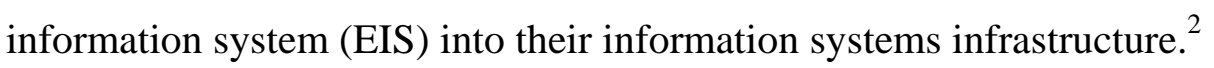

The theory of EIS implementation has been well covered by researchers. ${ }^{3}$ The purpose of this paper is to review how the theoretical approaches have been utilised by UK organisations. To achieve this a survey was conducted of companies that were known to be using, or considering the use of, an EIS. The successes and limitations of the system implementations are analysed from the survey. To augment the successes companies have achieved, lessons are identified from the implementation methods employed by comparing them with the theoretical approaches in the literature. These findings will be useful for organisations planning to introduce an EIS, or as a comparison for companies who already have installed a system. The results should also inspire further research about, and improvements of, the EIS development tools.

\section{Definition and Characteristics of an EIS}

Researchers have used a number of definitions for EIS. ${ }^{4}$ A general definition of EIS is given by $\operatorname{Bird}^{5}$ as: 'a computer software product, front-ended by a user-friendly terminal and software interface which electronically provides executives with rapid and reliable access to 
information regarding key areas of their business, helping them to perform their management functions and achieve their business objectives.'

Watson et.al. ${ }^{6}$ extend this definition to include access to internal and external information relevant to the critical success factors of the executive. An EIS is more than just a tool which only presents summarised data. One of the vital attributes is to be able to interrogate external information sources, such as demographic databases, international news and stock exchange information, and use them in association with internal information.

Enhancing the executive’s ability to communicate internally, with peers and subordinates, and with external contacts is an important function of these systems. In particular, the information discovered using the system should be easily communicated to others, perhaps through electronic mail or groupware technology. The terms executive information system and executive support system (ESS) are often used interchangeably. Carlsson \& Widmeyer ${ }^{7}$ suggest that ESS are EIS with electronic mail, decision support and office support facilities. The term EIS is used throughout this paper, but the study applies equally to both ESS and EIS.

It is suggested that the goals of an EIS should be to:

- $\quad$ reduce the amount of data bombarding the executive;

- increase the relevance, timeliness and continuing usability of the information that does reach the executive;

- enhance understanding of the data which is presented;

- facilitate communication with others. ${ }^{8}$ 


\section{The Survey}

Questionnaires were mailed to a selection of UK based organisations during the latter half of 1994. The survey population were predominantly chosen from the UK customer lists of two vendors of EIS tools. Fifty replies were received in total, from thirty different companies. Five of the companies returned null replies, as they did not currently utilise an EIS. The replies from the remaining twenty-five organisations are evaluated in this paper.

Two different questionnaires were used. The first was for computing or IS specialists involved in the development of the EIS to ascertain the technical aspects of the implementation. In particular, it looked at the methods and tools employed in developing the system. Nineteen companies responded to this questionnaire. The second was aimed at the executives (and/or other employees) who used the system. These reviewed how the systems were used and what information was obtained from them. Areas of concern or potential improvement were targeted in this questionnaire. Twenty-nine replies were received from fourteen different organisations.

Replies to the survey were received from across the UK. The organisations using EIS were involved in diverse businesses (see figure 1), including organisations such as hospital trusts and police forces, as well as manufacturers, local government and financial service companies. The size of companies using an EIS was also quite varied. The majority of questionnaires were returned from companies of between 1000 and 5000 employees. In some cases respondents did not answer every question. Percentages shown in the study are therefore based on the number of responses received for the given question. 

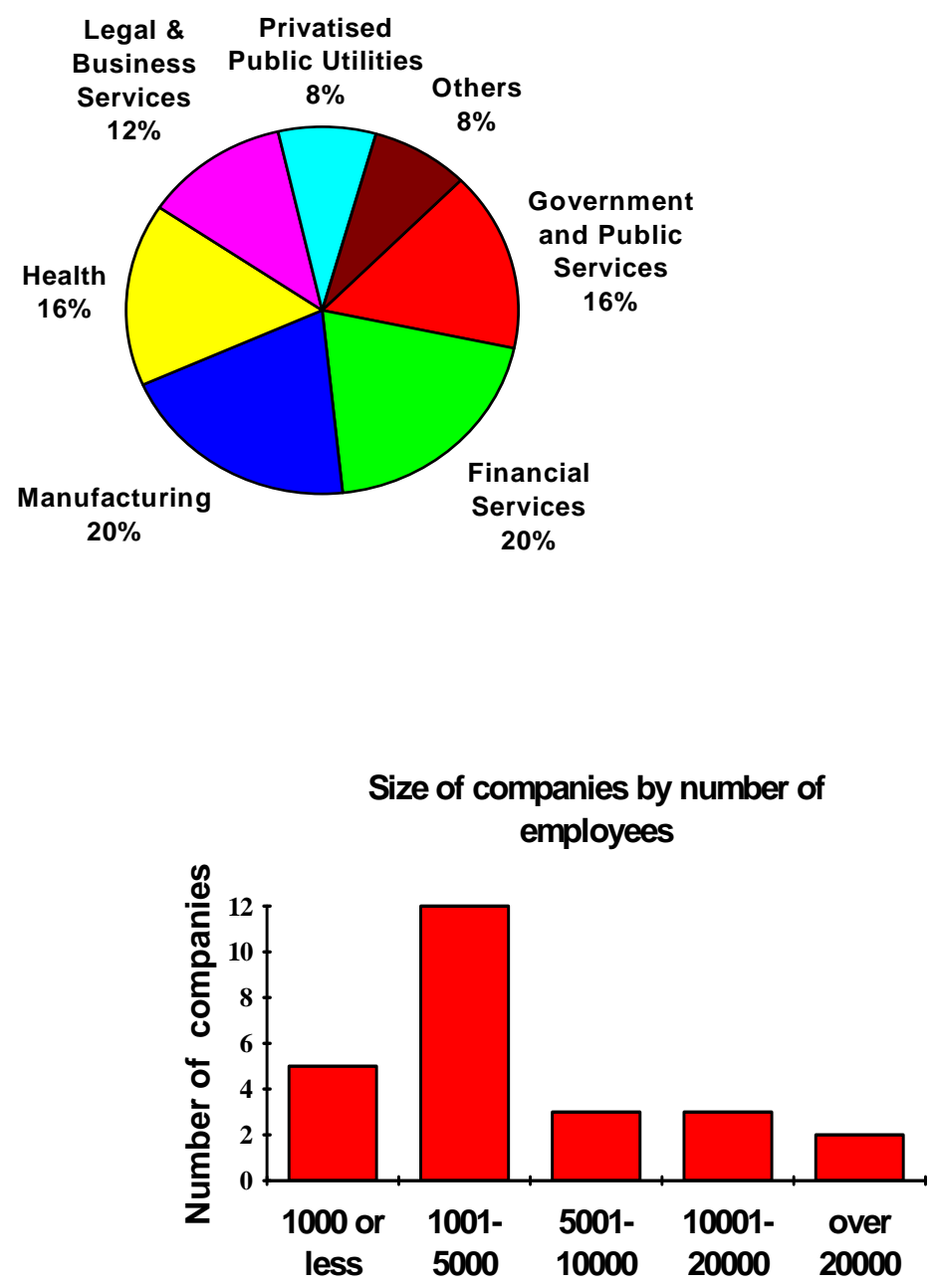

Figure 1. Respondents by business type and size of company

\section{Survey Findings}

Only if the EIS becomes the acknowledged vehicle for obtaining and communicating information will companies have achieved their objectives. In order for executives to spend their valuable time using the system, they have to be convinced that there is a clear benefit in doing so. It must provide something which they can not obtain elsewhere, whether it is different sources of information or the features to portray that information. Managers have 
been shown to prefer informal systems of gathering their information, ${ }^{9}$ therefore the novelty of the system will soon wear off if it does not give positive advantages.

The survey of executives and other users compared the EIS as a provider of information with the previous methods employed. The simplicity of the user interface is instrumental in the success of an EIS. This is especially true if the system is utilised by top management who are not comfortable with the technology. Only two respondents noted that they did not find the system easy to use. In a survey of US organisations who reported that their EIS had failed, 43 percent cited the complexity of the system as a reason for the failure. ${ }^{10}$ The outstanding area of success was the ability of an EIS to portray results in more appropriate formats. The study showed that 93 percent considered that the presentation of the information had improved as a result of the introduction of the EIS. This is chiefly a result of the high quality graphics available, thereby allowing patterns in the data to be easily visualised. In 85 percent of cases respondents stated that the information was also easier to access compared to previous methods. Features such as drill-down make the information more obtainable, exposing underlying trends or problems. As the data is in an electronic format it can be manipulated to analyse company performance.

To be useful information has to be timely, as decisions could be ill-informed if they are based on dated facts. To achieve this, the information has to be both available at the right time and for the time period required. The results of the survey (table 1) show that, compared to previous systems, it was quicker to access the information and that the underlying data was more up to date.

Information Attribute Improved (\%)

No change (\%) Worse (\%) 


\begin{tabular}{|l|c|c|c|} 
Presentation & 93 & 7 & 0 \\
\hline Ease of Access & 85 & 15 & 0 \\
\hline Up to date & 85 & 15 & 0 \\
\hline Speed of access & 81 & 19 & 0 \\
\hline Information Sources & 67 & 33 & 0 \\
\hline
\end{tabular}

Table 1. Quality of EIS information compared to prior methods

When implementing an EIS one of the main reasons for failure is that the objectives of the executives are not met by the system. ${ }^{11}$ Making sure that the system provides the correct information is a key element in the development process. The study showed (table 2) that by far the largest set of information being used by the executives was internal key performance indicators, typically sales or productivity performance. The information was being used for the day to day control of the organisation (table 3). The indicators allowed early identification of problems or potential improvements in the operation of the business. These findings correspond with those of Millet and Mawhinney ${ }^{12}$ who found, in their study of US organisations, that 81 percent of EIS were predominately oriented towards monitoring the business akin to a traditional management information system. 


\begin{tabular}{|l|c|}
\hline & respondents \\
\hline Sales information (new / progress) & 73 \\
\hline $\begin{array}{l}\text { Business performance (e.g. waiting lists, crime } \\
\text { clearance, contracts, service levels, productivity) }\end{array}$ & 55 \\
\hline Financial Information / Results & 25 \\
\hline Manpower Figures / Recruitment & 23 \\
\hline Business Expenses / Costs & 23 \\
\hline Investment / Share News & 20 \\
\hline Electronic Mail (internal \& external) & 10 \\
\hline Business News / Industry Results & 10 \\
\hline Profitability & 8 \\
\hline Competitor Information & 8 \\
\hline Customer / Distribution Information & 8 \\
\hline Stock & 5 \\
\hline Market Research & 5 \\
\hline
\end{tabular}

Table 2. Information available on the systems

\begin{tabular}{|l|c|}
\hline How Information is Used & $\begin{array}{c}\text { Percentage of managers } \\
\text { using system in this way }\end{array}$ \\
\hline Monitoring Progress & 44 \\
\hline Internal reporting / communication & 33 \\
\hline Identifying Issues / Early Warning (e.g. hold-ups) & 15 \\
\hline Improving the performance of the business & 11 \\
\hline Analysis of business & 11 \\
\hline External Reporting & 8 \\
\hline Trend analysis & 8 \\
\hline Background Information & 8 \\
\hline
\end{tabular}

Table 3. How the information is used

In the survey, 75 percent of the systems being used had planning facilities, either via modelling capabilities or trend analysis. Although 85 percent of respondents stated that they were better prepared for making decisions as a result of the system, only six of the twentyseven were using the system as their primary source for planning or decision making. As can be seen in figure 2, the others were using other computer systems or existing paper reports. The reason for not using the system for planning purposes varied from the system being too limited difficulty of use. Of those using the system for planning, most were using it for 
forecasting the future from past trends, for such items as sales, patient arrivals, insurance policy lapses or expense budgets. A few were looking at the external data to predict market changes or were using the data available to do "what-if” analyses for looking at alternative options.

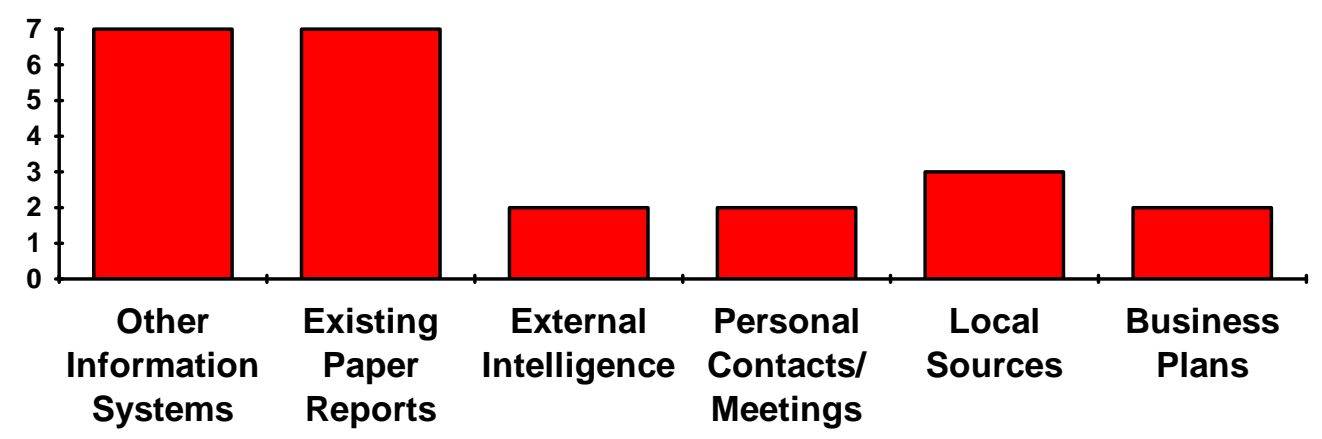

Figure 2. Main Sources of Information for Planning \& Decision Making

Many of the respondents wanted to see different or new information on their system, and improvements in the usability. The information demands were classified into three groups: further internal information to be used for monitoring, analysis and projection of data for planning, and external information (see table 5). The users' suggestions for improvements are shown in table 6. These are also grouped into categories: improvements to the user interface, functions available, characteristics of the information and how the system was implemented. 


\begin{tabular}{|l|l|l|}
\hline Internal Information & Planning / Analysis & External Information \\
\hline $\begin{array}{l}\text { Orders / Imminent Sales } \\
\text { Profitability }\end{array}$ & $\begin{array}{l}\text { Projections } \\
\text { Manpower / Deployment }\end{array}$ & Workflow \\
Cost / revenue & $\begin{array}{l}\text { Competitor information } \\
\text { Industry Statistics } \\
\text { Finance }\end{array}$ & $\begin{array}{l}\text { Demographies } \\
\text { (e.g. disease incidence) }\end{array}$ \\
Text & & \\
All Management Reports & & \\
More financial reports & & \\
Administration Statistics & & \\
Service Level & & \\
\hline
\end{tabular}

Table 5. Additional information requested by users

\begin{tabular}{|l|l|}
\hline User Interface & $\begin{array}{l}\text { Information Characteristics } \\
\text { Use of "Windows" as a user interface }\end{array}$ \\
$\begin{array}{l}\text { Faster retrieval } \\
\text { Better graphs } \\
\text { Changes to presentations \& pathways } \\
\text { More information per screen }\end{array}$ & $\begin{array}{l}\text { Monger history of data } \\
\text { More accurate information } \\
\text { More information on competitors } \\
\text { More comprehensive view of the business } \\
\text { environment }\end{array}$ \\
$\begin{array}{l}\text { Functions } \\
\text { "What-if ?" capability } \\
\text { Automatic calculations } \\
\text { Drill down ability } \\
\begin{array}{l}\text { Forecasts need to be more user friendly } \\
\text { More analysis of trends } \\
\text { More dimensions available for data analysis }\end{array}\end{array}$ & \\
\end{tabular}

Table 6. Users ideas for improvements to the system

The implication of the study is that systems primarily focus on daily performance, for which the systems are very well suited. As a result of this success, the respondents would like to see the provision of internal data extended. Many of them also recognised, that to maximise the potential of the system, it was necessary to be able to use the system for planning. To achieve this goal, improvements for both the data and the functions are required. In a study of executive activities, McLeod and Jones ${ }^{13}$ discovered that 43 percent of their incoming information transactions resulted from external sources. Data from external sources, 
especially competitor related information, was of paramount importance to respondents. Approximately half of managers were either using external data on the system or desirous of it. This information could augment the internal knowledge and performance data to expand the planning capabilities. Additionally, the planning functions on the system need to be tailored to the individual's requirements. ${ }^{14}$ Some may require very complex modelling capabilities and others only to project current trends into the future.

The purpose of EIS is to improve managerial functions at an executive level within the organisation. ${ }^{15}$ However, in less than a quarter of the organisations were board level or senior management the sole users of the system. Also, in less than one-third of the organisations were board level executives using the system at all. The systems were being used by middle management in approximately 40 percent of the cases, and also by specialist staff (e.g. marketing, finance, planners, surveyors) in a different 40 percent of organisations. Millet and Mawhinney ${ }^{16}$ similarly found only 28 percent of the users were executives, with middle management and professional specialists accounting for the others.

There are three possible reasons for the low proportion of executive users. Executives have previously to rejected the need for information technology in their offices. ${ }^{17}$ However, according to Armstrong ${ }^{18}$ the executive culture is changing. There is a developing reliance on information technology as they become more computer literate. Secondly, 10 percent of the systems reviewed were dedicated to a limited section of the organisation and therefore would not be applicable to the strategic thinking of many of the organisation's executives. Alternatively, the information and planning needs of executives are not being met by the system, and therefore they have regressed to previous methods. The situation can be attributed to a combination of these factors. 


\section{Successful Implementations}

Lilley ${ }^{19}$ asserts that EIS can disable the executive's creativity and therefore it is better that such systems are not used at the very top of the organisational hierarchy. However, if EIS are to be applied successfully at the apex of the organisation then senior management need to be suitably supported by the system. The development methods must ensure that this happens. Factors that Barrow, and DeLong and Rockart ${ }^{20}$ identified as significant in successful implementations are summarised below.

1. A committed and informed executive sponsor.

2. Link information requirements to business objective(s).

3. Ensure feasibility of data availability.

4. Use appropriate development resources.

5. Managing the implementation and evolution.

The remainder of the paper will discuss how the organisations in the achieved each of these factors. Comparisons are made between the methods employed by the organisations in the study and methods identified in the literature. By drawing on global experience, organisations will be able to apply maturer techniques when developing and implementing EIS.

\section{Executive Sponsorship}

A recurring theme in the literature is the importance of the executive sponsor or champion. Glover et. al. ${ }^{21}$ found lack of sponsorship to be the most common cause when an EIS failed.The sponsor has to be organisationally powerful so that key decisions about the development can be taken and they can become an active promoter of the system amongst 
their peers. They also have a crucial part to play in helping to derive the information requirements of the management team.

In the survey, over half of the organisations set up a working party or steering committee to decide the requirements for the system. The executives, either collectively or through an appointed individual, were heavily involved in deciding how the system should work (table 7). All companies had involved at least one business representative in the development. In many cases the Finance Director, or other key member of the Finance Department, performed the role of sponsor in the development. The principles of the literature had been applied by most organisations. For the system to be truly executive oriented the sponsor should be the Chief Executive Officer, or a suitable deputy. In a more specialised system the sponsor should be the executive for the particular division involved.

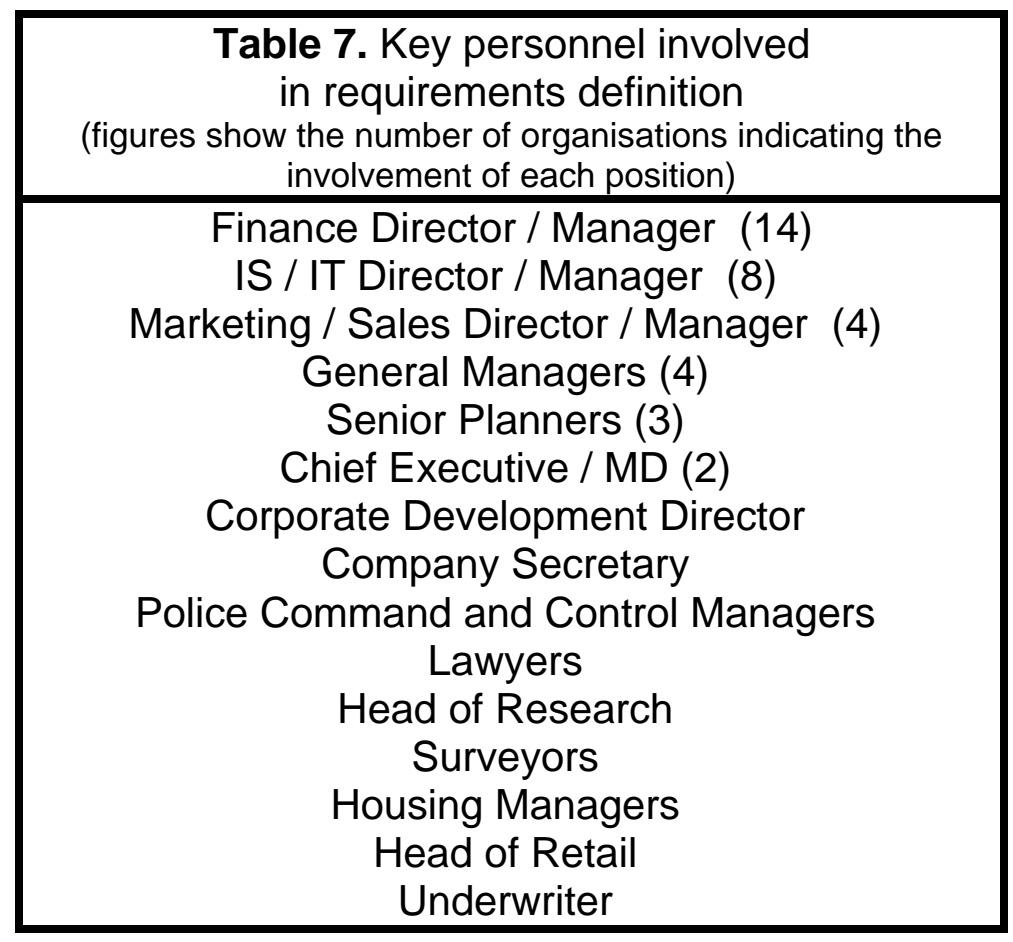

\section{Determining the Information Requirements}


Deciding upon the information requirements of the executives is one of the most difficult, and yet crucial, parts of the development of an EIS. Identifying the correct information needs can prove to be elusive. The creation of a set of universal requirements based on organisational goals is especially difficult. A major stumbling block is that even when executive time is given to assist in the analysis process, it is difficult for them to identify their needs. Of course an executive will try to identify items of importance, but the tendency is to focus on items which have been important in recent days or weeks. The process inevitably leaves out vital information. ${ }^{22}$ According to Millet and Mawhinney ${ }^{23}$ the full value of an EIS will only be realised when the system helps executives focus on strategic issues. To solve this problem, Watson and Frolick ${ }^{24}$ apply four strategies for determining information requirements: (1) asking (2) deriving from existing system (3) synthesis from characteristics of the utilising system, and (4) discovering from experimentation with an evolving information system.

The typical approach of many analysts to identifying requirements in any information system is to ask "what information do you need?" This leads to frustration on both sides. It is inevitable that the executive will forget items. The analyst may not have the comprehension to be able to intuitively make the same assumptions as the executive. Wetherbe ${ }^{25}$ suggests the use of group discussions for joint application design. By putting people together the synergy of the group leads to a pooling of ideas and conflicting objectives of different functional areas can be resolved. Group sessions are to be followed by a structured interview with each executive. The interview can take different forms, but should look to draw out the requirements by phrasing the questions for most effective response. Wetherbe ${ }^{26}$ advises using questions derived from three different methods: 
- Business Systems Planning (specify problems and decisions)

- Critical Success Factors (specify CSFs and the information required to monitor them)

- End/Means (specify effectiveness criteria for outputs and efficiency criteria for processes used to generate output).

Watson \& Frolick ${ }^{27}$ propose looking at the daily activities of an executive or ask questions such as "what would you want to know after a vacation?” They also note that it helps to focus the discussion if the analyst prepares sample screens.

Approximately a third of the EIS development teams stated that they had used interviews or group workshops. The study revealed that organisations adopted individual interviews as a means of discussion. These discussions were either driven from written requirements as drawn up by the executive or an initial screen prototype created by the IS team. However, two firms applied Wetherbe’s suggestion by combining the use of one-to-one sessions and group workshops.

The business strategy was used as a starting point for group discussion by 15 percent of the companies. By identifying areas that are important for the successful running of the business, the system can be tailored to the executives' requirements. The advantage of this top-down approach is that the focus is on the information for the areas of the business which are important for future success. The risk of starting from the detail in the executive's mind is that the scope can be limited to the urgent and short-term information requirements. 


\section{Data Availability}

As stated earlier, Watson and Frolick suggest existing systems can be used to examine the data available and currently used. Of the organisations in the study, only 12 percent analysed the data available on current systems to identify potential data for the EIS. The results of this were then used to create sample screens for the initial discussion. At Lockheed-Georgia, ${ }^{28}$ the EIS team asked each executive's secretary to identify which reports fell into each of the following categories:

1. those put on the executive's desk;

2. those filed and frequently retrieved at the executive's request;

3. those filed and seldom retrieved.

This determined the information that was required most frequently. However, this process can not be used to identify potential external information or the functions required. It should therefore be used in combination with the methods described above. To identify the data available externally can again help to focus the ideals of an executive so that they are projected onto that which is achievable.

IS management should identify realistic goals, based on data they know is available, and not promise more than they can deliver. ${ }^{29}$ This can be a problem when assessing the availablity of historic data for identifying trends. Friend ${ }^{30}$ gives an example of how executive confidence can be easily undermined by a lack of business knowledge and technical forethought. A Marketing Vice-President attending a demonstration requested a chart of product sales for the past five years. Due to the quantity of data and an operating system change a year previous, this data was no longer accessible. The expectation of the IS team 
was that a lot of detail of current operations was more important than historical data, a mistaken assumption in this case. The Vice-President walked out of the demonstration.

\section{Use Appropriate Development Resources}

An EIS can be developed by using software developed in-house specifically for the system or general software tools produced by vendors. Given the nature of the survey sample, the majority of organisations used vendor-supplied development packages. In a survey of US firms, 24 percent of firms used in-house developed software, 24 percent used vendorsupplied software and $52 \%$ used a combination of the two. ${ }^{31}$

Internal development staff were used by the majority of organisations (see figure 3). Many of the firms had created multi-disciplinary teams to develop their systems, mixing technical and business skills to ensure the appropriate skill base was available. The key skills required are the ability to work with executives, communicate and understand the business, as well as strong technical skills. ${ }^{32}$ Many organisations (44 percent) made use of external expertise. The source of these skills was normally the software vendor, although one organisation employed an independent consultant to guide them. Only 14 percent of US organisations reported using vendor personnel to develop their system. ${ }^{33}$ To use experienced EIS developers will enhance the chance of success. If an organisation does not have such skills, then external assistance should be sought thereby reducing the risk of failure. The initial development phase can be used to transfer these skills to in-house developers. 


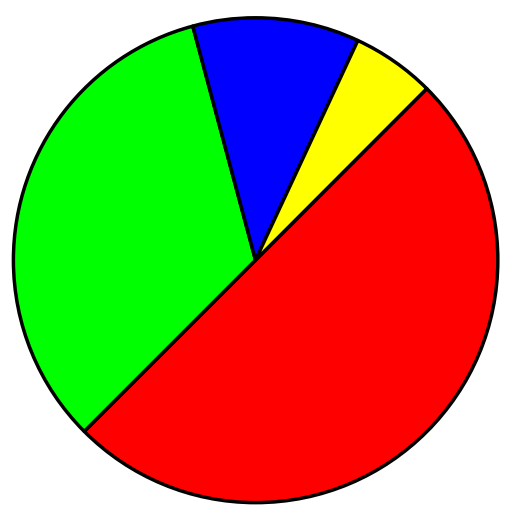

$\square$ Internal Development (with non-computing staff)

$\square$ External Source

$\square$ Combination of Internal \&External

$\square$ Non-Computing Staff only

Figure 3. Who developed the system?

\section{Managing the Implementation and Evolution}

An adaptive methodology has been applied to decision support systems ${ }^{34}$ and can be applied equally well to EIS. The development is dealing with the unknown and uncertainty is therefore widespread. Early results are very important to overcome these fears and build confidence for the future. The idea of developing a small system and evolving the system to include further business areas and functions reduces the risk of failure. If a system takes a long time to plan, specify and develop it is likely to end in failure. ${ }^{35}$

The initial system should be based in a likely success area, with functions which would be core to any EIS. Jordon ${ }^{36}$ suggests developing the initial system for the Chief Information Officer. For this system he suggests the core elements should be: financial control; human resources; and system productivity/transaction processing costs. By minimising the scope the task of identifying the requirements is made easier. The time to develop the initial system is also reduced, enabling the ideas put forward to bear fruit quickly. By gradually introducing 
the system, the learning curve is also easier for executives. ${ }^{37}$ Two organisations mentioned using continuous development and another 6 monthly periodic reviews. The idea of continually adapting the system to meet the current need is appropriate to this type of system. Moreover, some organisations indicated that they split the requests into major or minor developments. The minor developments being part of the continuous development and the major (caused perhaps by business change) being formed into separate projects on their own, as per the adaptive methodology.

As stated earlier, the system needs to combine internal and external information sources. For early implementation internal data is readily available and should, therefore, form the predominate part of the initial system. It is recommended that easily attainable external information is identified and introduced into the system at an early stage in the system's life cycle. This will ensure that executives' interest will be maintained and early benefits derived from using the system.

This idea of gradually evolving the system can be combined with the use of a prototyping method for each phase. A protoyping approach was popular with the organisations surveyed, with 30 percent of them applying this method, as it is important for managers to be able to refine their ideas through trial and error. ${ }^{38}$ Experiential learning is often used by people for turning a conceptual idea into a detailed specification.

An important factor in the success of an EIS is how relevant the information available on the system is to the decisions being made by the users. If the information becomes irrelevant then the managers will revert to using alternative mechanisms for finding the facts, or perhaps worst of all assumptions are made when making key decisions. It is therefore essential that 
the system changes with the business. The business can not be restricted by the system. The IS department should monitor activity on the system. Are certain screens not being used any more? Do individuals no longer use the system? These and other factors can be a sign that the system and the business have drifted apart. ${ }^{39}$ In the study it was clear that the users were the driving force for change, either through individual requests (56 percent) or via a user group (25 percent). However, organisations allowed requests to flow in an ad-hoc manner, rather than continually prompting and checking to see if the system is meeting current business needs.

A method of identifying change is important. The IS department should be able to react quickly to business driven change. In many IS departments a formal change request process will have been set up for the core business systems. However, a paper or electronic based system may only partially answer the need for EIS. A regular review meeting of an executives user group or a series of individual meetings could be held. A formal change request could be raised from points identified in the meeting.

\section{Conclusion}

The survey has identified how executive information systems are being used within the UK. The indication from the study is that the systems are replacing the traditional paper based systems for monitoring the progress of key areas of the business. This is due to the immediate and more flexible nature of the system when compared with a traditional fixed format reporting system. The majority of people using the systems were very positive about its ease of use and the extra information provided through the system. Also, quite often companies are looking for more than just a reporting system, by linking the past information into supporting decisions on future changes. However, there is still a need for further culture 
change before such systems are fully utilised and become the main source of facts for planning and decision making. The systems need to be designed with this in mind.

The methods currently employed by organisations in the development of their systems partially reflect the methods identified in the literature. However, the lack of experience and formalised methods is reflected in the limitations of the current implementations. The literature has provided an abundance of theoretical approaches for practitioners to follow. Organisations new to EIS need to recognise that they are a different type of IS and therefore need a different development approach. A multifaceted methodology is required for successful identification of requirements and develop a successful system. By following the guidelines outlined in the paper and recognising the successes and pitfalls of other organisations then executives will begin to fully exploit the technology available to them. 


\section{REFERENCES}

1. GALLIERS, R.D., YASMIN, M. AND SPEARING, L. (1994). Coping with information technology? How British executives perceive the key information systems management issues in the mid-1990s, Journal of Information Technology, 9, pp.223-238.

2. FRIEND, D. (1988). EIS : Straight to the Point, Information Strategy: The Executive's Journal, 4 (Summer), pp.25-30.

3. ROCKART, J.F. AND DELONG, D.W. (1988). Executive support systems: the emergence of top management computer use. Homeward, IL: Dow Jones-Irwin; WETHERBE, J.C. (1991). Executive information requirements : getting it right, MIS Quarterly, pp.51-65; WARMOUTH, M.T. AND YEN, D. (1992). A detailed analysis of executive information systems, International Journal of Information Management, 12, pp. 192-208; GLOVER, H., WATSON, H.J. AND RAINER, R.K. (1992). 20 Ways to waste an EIS investment, Information Strategy: The Executive's Journal, 8 (Winter), pp.11-17; FRIEND, D. (1986). Executive information systems: success, failures, insights, and misconceptions. In: DSS-86 Transactions The Institute of Management Sciences, Providence, RI, pp. 35-40.

4. ROCKART AND DELONG, Op. cit., Ref. 3; FRIEND, Op. cit., Ref. 3; MILLET, J. AND MAWHINNEY C.H. (1990). $\quad$ EIS versus MIS: a choice perspective. In: Proc 23rd Hawaii International Conference on System Science IEEE Computer Society Press (R.H. Sprague Jr., ed.), Los Alamitos, CA, pp. 202-209.

5. BIRD, J. (1992). Executive information systems management handbook. Oxford: NCC Blackwell.

6. WATSON, H.J. \& RAINER, K.R. JR. \& KOH, C.E. (1991). Executive information system: a framework for development and a survey of current practise. MIS Quarterly, pp. 12-30. 
7. CARLSSON, S. A. \& WIDMEYER, G.R. (1990). Towards a theory of Executive Information Systems. In: Proc 23rd Hawaii International Conference on System Science IEEE Computer Society Press (R.H. Sprague Jr., ed.), Los Alamitos, CA, pp. 195 -201.

8. Op. cit., Ref. 5.

9. MCLEOD, R. JR. AND JONES, J.W. (1986). Making executive information systems more effective. Business Horizons,29 (5), pp.29-37.

10. GLOVER, WATSON AND RAINER. Op. cit., Ref. 3.

11. GLOVER, WATSON AND RAINER. Op. cit., Ref. 3.

12. MILLET AND MAWHINNEY. Op. cit., Ref. 4.

13. Op.cit., Ref. 9.

14. ROCKART, J.F. AND TREACY, M.E. (1982). The CEO goes on-line. Harvard Business Review, 60 (4), pp 84-88; MCLEOD AND JONES. Op.cit., Ref. 9.

15. Op. cit., Ref. 7; ROCKART AND DELONG. Op. Cit., Ref. 3.

16. Op. cit., Ref. 12.

17. Financial Times, March 1, 1990 quoted in LILLEY, S. (1992), Overcoming the disabling effects of executive information systems. Journal of Information Systems, 2, pp. 281-292.

18. ARMSTRONG, D.A. (1990). The people factor in EIS success. Datamation,(April 1), pp. 73-79.

19. LILLEY, S. (1992), Overcoming the disabling effects of executive information systems. Journal of Information Systems, 2, pp. 281-292.

20. BARROW, C. (1990). Implementing an executive information system: seven steps for success. Journal of Information System Management, 7 (2), pp.41-46. DELONG, D.W. AND ROCKART, J.F. (1986). Identifying the attributes of successful executive support system implementation. In: Transactions of the Sixth International Conference on Decision Support Systems 1986.?? 
21. GLOVER, WATSON AND RAINER. Op. cit., Ref. 3.

22. WETHERBE. Op. cit., Ref. 3.

23. Op. cit., Ref. 12.

24. WATSON, H.J. AND FROLICK, M.N. (1993). Determining information requirements for an EIS. MIS Quarterly, pp.255-269.

25. WETHERBE. Op. cit., Ref. 3.

26. WETHERBE. Op. cit., Ref. 3.

27. Op.cit., Ref. 24.

28. HOUDESHEL, G. (1990). Selecting Information for an EIS: Experiences at LockheedGeorgia. In: Proc 24th Hawaii International Conference on System Science IEEE Computer Society Press (J.F. Nunamaker Jr., ed.), Los Alamitos, CA, pp.178-185. 29. BARROW. Op. cit., Ref. 20.

30. FRIEND. Op. cit., Ref. 3.

31. Op. cit., Ref. 6.

32. DELONG AND ROCKART. Op.cit., Ref. 20; BARROW. Op. cit., Ref.20; Op. cit., Ref. 6.

33. Op. cit., Ref. 6.

34. Sprague - from DSS putting theory into practice

35. FRIEND. Op. cit.,Ref. 3.

36. JORDON, E. (1993). Executive information systems for the Chief Information Officer. International Journal of Information Management, 13, pp.249-259.

37. FRIEND. Op. cit.,Ref. 3.

38. WETHERBE. Op. cit., Ref. 3.

39. Op. cit., Ref. 23. 